\title{
KAJIAN GENDER DALAM ILMU KOMUNIKASI
}

\author{
Roro Retno Wulan \\ Telkom University Bandung \\ rorowoeloan@telkomuniversity.ac.id
}

\begin{abstract}
Abstrak
Ilmu Komunikasi sebagai cabang ilmu pengetahuan adalah ilmu yang dinamis. Perkembangan peradaban manusia menjadi titik tolak perkembangan keilmuannya. Manusia tidak dapat menafikkan adanya komunikasi dalam relasi di kehidupannya. Maraknya kajian atas kondisi perempuan mendorong geliat Ilmu Komunikasi untuk membongkar epistemologi keilmuannya. Tulisan ini adalah sebuah penggalian atas teoriteori Komunikasi yang didedikasikan kepada riset atas perempuan. Riset yang berkaitan dengan posisi perempuan erat dengan dominasi patriarki secara ekonomi, politik dan sosial. Perempuan menjadi subjek atas dirinya dan bukan menjadi objek seperti yang terjadi selama ini. Di mulai dari kajian filsafati pemikiran feminis hingga epistemologi feminisme. Keunikan dari tulisan ini adalah ibarat sebuah rangkuman beberapa teori femnisme yang lahir dari ranah komunikasi. Kesimpulan yang diraih adalah ragam pengetahuan terrsebut menjadi bekal bagi para periset dan pemerhati kajian perempuan di ranah Ilmu Komunikasi. Ke depannya teori mengenai feminisme ini akan membantu perkembangan Ilmu Komunikasi dalam mendekonstruksi metode dalam melakukan risetriset tentang perempuan di Indonesia.

Kata kunci: feminisme, gender, perempuan, dominasi, patriarki
\end{abstract}

\section{Pendahuluan}

Berkembangnya ilmu pengetahuan tidak bisa dilepaskan dari munculnya masalah-masalah sosial yang ada. Ilmu Komunikasi sebagai ilmu yang dinamis mencoba memotret kondisi sosial yang ada. Banyaknya peneliti yang mencoba menjajaki solusi atas masalah-masalah sosial tersebut membuahkan beberapa hasil di antaranya adalah munculnya kajian feminisme dalam Ilmu Komunikasi. Bagaimana teori dan metode dalam kajian ilmu komunikasi berkelindan dalam penyelesaian permasalahan perempuan.

Kajian feminisme erat kaitannya dengan posisi perempuan yang dianggap tidak sederajat dengan kaum laki-laki. Penelitian perempuan lebih banyak bermain pada permasalahan ketimpangan kedudukan dan posisi perempuan, tubuh dan identitas perempuan, sertaseksualitas yang erat dikaitkan dengan perempuan. Penelitian mengenai 
perempuan berupaya mengembalikan hak-hak perempuan melalui ranah keilmuan. Tulisan kali ini menekankan riset mengenai masalah perempuan pada ranah Ilmu Komunikasi. Kegiatan yang dilakukan dalam penelitian mengenai perempuan ini adalah penelitian yang bertujuan untuk mendudukkan masalah perempuan dalam pandangan perempuan. Selama ini kasus mengenai perempuan masih diselesaikan dengan gaya dan pandangan patriarki. Tentunya tidak memihak perempuan. Solusi dari permasalahan perempuan, masih dianggap tidak memenuhi harapan perempuan. Akibatnya kebijakan mengenai perempuan pun dipandang sama rata dengan laki-laki.

Permasalahan perempuan memang unik. Perempuan mampu menginternalisasi tekanan dan penderitaan yang dialami. Perempuan diajarkan untuk tutup mulut hingga perempuan tidak mampu mewakili dirinya sendiri. Kesulitan perempuan adalah milik perempuan dan diabaikan karena sifatnya personal, berbeda dengan masalah laki-laki yang mampu menjadi agenda makro. Pada kenyataannya ada hal-hal yang berkaitan dengan perempuan yang tidak menjadi beban laki-laki, misalnya masalah reproduksi, masalah bentuk tubuh, dan masih banyak masalah lain yang membuat perempuan perlu ditangani berbeda dari laki-laki.

\section{Perbedaan penelitian perempuan dengan penelitian gender}

Berdasarkan pendapat Cherish Kramarae \& Paula Treichler: "Feminism is the radical notion that women are people". Mengapa demikian? Kajian perempuan merupakan salah satu kajian di ranah kritis karena mempertanyakan kebenaran posisi perempuan dalam kehidupan, baik kehidupan keilmuan atau kehidupan bermasyarakat. Dalam pandangan kaum feminis menjadi perempuan atau laki-laki adalah terjadi ketika kita dibesarkan. Masyarakatlah yang menentukan kita menjadi perempuan dan menjadi laki-laki. Pola asuh, adat istiadat dan agama adalah nilai dan norma yang dipelajari oleh generasi ke generasi bagaimana menjadi perempuan ataupun laki-laki. Menjadi salah satu 
gender lebih banyak peranan aspek nurture daripada nature. Lebih banyak bagaimana komunikasi dalam lingkungan keluarga membentuk seseorang daripada aspek kondisi alamiahnya. Contohnya anak laki-laki bermain mobil-mobilan, memanjat pohon, atau bermain sepak bola. Di sisi lain anak perempuan bermain masak-masakan, bermain boneka dan lebih banyak aspek domestik yang ditawarkan. Jika salah satu gender memainkan permainan gender lain, masyarakat akan melakukan koreksi. Lingkungan yang patriarki memunculkan generasi yang patriakis pada akhirnya.

Kata "gender" seringkali dipertukarkan dengan kata "seks". Penggunaan kata “gender” berawal dari abad ke 14 dan sering dipergunakan dalam konteks Sosiologi awal pada 1900-an. Konsep sosiologis feminis pertama sebagai bentuk pembeda atribut-atribut yang ditentukan secra biologis dan perilaku-perilaku yang dipelajari secara sosial lahir dari karya Charlotte Perkins Gilman dalam bukunya "Woman and Economics” (1898). Menurut Mansour Fakih (2012: 8) Gender adalah suatu sifat yang melekat pada laki-laki atau perempuan yang dikonstruksi secara sosial ataupun kultural.

Selain kajian feminisme yang berbicara tentang posisi perempuan, terdapat kajian gender yang memiliki ranah cakupan lebih luas hingga bahasannya masuk ke kelompokkelompok lesbian, gay, biseksual, maskulinitas dan transgender. Dalam tulisan ini penulis akan lebih memperdalam konteks kajian perempuan dalam komunikasi dimulai dari pandangan-pandangan filsafat Barat tentang perempuan. Secara keilmuan, komunikasi tidak menampik fenomena gender ini. Oleh karena itu telah muncul beragam teori Queer dalam kajian Ilmu Komunikasi (Littlejohn dan Foss, 2008).

Penelitian dalam ranah feminis ini masih banyak mendapat tentangan dan cibiran di masyarakat. Alasannya adalah konsep feminis sendiri lahir di Barat. Sebagai produk Barat tentunya nilai-nilai feminis bertentangan dengan budaya Timur. Uniknya dalam praktek kehidupan sosial Timur juga memilikinya. Misalnya budaya matrilinial 
masyarakat Minang dan beberapa suku di Sumatera. Bahkan masyarakat Minang diklaim sebagai kelompok matrilinial terbesar di dunia.

\section{Filsafat dan feminisme}

Dari sisi filsafati, sebagai science materna, ibu dari semua ilmu pengetahuan. Filsafat berperan melahirkan banyak ilmu, namun sifat feminin dari Filsafat tidak nampak dalam perkembangan filsafat selanjutnya. Filsafat kontemporer lebih dikenal sebagai Philosophy of Man, oleh karenanya kaum feminis memandang bahwa filsafat sebagai cara berpikir maskulin. Di sisi lain, sebagai science materna, pada kenyataannya banyak filsuf yang tidak memiliki kesadaran akan posisi perempuan dalam kehidupan. Kondisi ini menjadi sebuah pembahasan yang sangat menarik. Berikut mengutip pendapat beberapa filsuf besar mengenai posisi laki-laki dan perempuan:

1. Descartes: menyatakan konsep dualisnya dengan slogan yang terkenal "Cogito Ergo Sum” (I think therefore I am) di mana pernyataan itu membuktikan bahwa manusia adalah mahluk dualis, karena memiliki pemikiran-pemikiran spiritualis dalam tubuh material. Kegiatan berpikir diinterpretasikan sebagai kegiatan lakilaki. Perempuan dianggap tidak berpikir. Dalam pembahasan budaya maka pernyataan itu menjadi "laki-laki berpikir maka laki-laki yang ada (mengetahui)".

2. Francis Bacon: merupakan salah seorang filfuf yang menanggap bahwa perempuan merupakan rintangan untuk maju. “...yang jelas pekerjaan yang paling baik dan dipersembahkan keada publik dihasilkan dari laki-laki yang tidak menikah atau tidak memiliki anak, yang sebenarnya baik secara afeksi atau penuh makna telah menikah dengan publik". Pernyataannya ini menjadikan perempuan sebagai hambatan dalam peradaban dan fungsi perempuan lebih pada konsep prokreasi. 
3. Hobbes dan Locke: memiliki pandangan yang sama bahwa laki-laki dan perempuan memiliki tanggung jawab dan kekuasaan yang sama terutama atas keberhasilan keluarga. Bagi Hobbes hak patriarkal yang murni tidak dapat dipertanggungjawabkan. Locke menganggap bahwa kekuasaan keluarga terletak secara egaliter antara ayah maupun ibu.

4. Hume: memiliki kritik menarik berkaitan dengan teori kontrak sosial terutama antara laki-laki dan perempuan. Menurutnya keadilan terhadap perempuan tidak akan benar-benar tercapai. Pertama karena ada kenyataan bahwa perempuan selalu terpinggirkan dalam masyarakat. Kedua, perempuan lemah bukan karena kodratnya tetapi karena situasi sosial yang dihadapinya.

\section{Kajian Teoritis}

Dalam perkembangan Ilmu Komunikasi kita mengenal munculnya perspektif kritis. Perspektif ini didasari dari adanya kesadaran bahwa pesan komunikasi "reinforce oppresion in the society", sehingga bukan hanya aksi sosial namun juga teks-teks turut melanggengkan kekuasaan dan dominasi ideologi patriarki. Perspektif kritis mengajak kelompok yang termarginalkan untuk bangkit dan menggugah kesadarannya agar mampu memberdayakan dirinya bukan hanya menangisi keadaan. Perspektif kritis mengajarkan posisi berdiri untuk membela hak dan posisi kaum-kaum termarginalkan. Tradisi kritis juga melibatkan banyak tradisi lain dari Komunikasi yang pada dasarnya berupaya untuk menolak dan resistensi terhadap tradisi-tradisi lama. Littlejohn \& Foss (2008: 45) berpendapat "These theories are concerned with how power, oppression, and privilege are the products of certain forms of communication throughout society, making the critical tradition significant in the field of communication theory today”. Kajian kritis menurut Littlejohn \& Foss (2008:46) berupaya untuk: 
a. Melihat kekuasaan, kepercayaan, ideologi yang mendominasi secara terselubung ada dalam masyarakat.

b. Berupaya membuka tabir kondisi sosial yang tertekan atau tertindas dan pengaturan kekuasaan dalam rangka meningkatkan emansipasi dalam pengertian membebaskan dan memberikan kesadaran.

c. Teori dalam Tradisi Kritis secara sadar memadukan teori dan aksi, oleh karena itu teori kritis lebih banyak bergerak dalam kajian kaum marginal.

Tradisi Kritis melihat Komunikasi tidak dapat dipisahkan dari faktor lain yang ada dalam keseluruhan sistem. Littlejohn \& Foss (2008: 47) menambahkan empat cabang baru dalam teori kritis sejalan dengan pesatnya pengaruh tradisi Kritis dalam penelitian Komunikasi, yaitu posmodernisme, postrukturalisme, pascakolonial, dan kajian feminis.

Walby (1990), Storey (2012), dan Ida (2014) melihat sedikitnya terdapat empat bentuk perjuangan perempuan yang berbeda sebagai respon tekanan yang perempuan hadapi, yaitu radikal, marxis, liberal dan "dual systems theory”. Jika kelompok radikal menganggap opresi terhadap perempuan adalah akibat tekanan kaum patriarki, maka kaum marxis melihat penderitaan perempuan diakibatkan kekuasaan kaum pemodal terhadap buruh. Di sisi lain kaum liberal melihat tekanan terhadap perempuan adalah akibat munculnya kepentingan kaum laki-laki yang menekan kehidupan perempuan sehingga hak-hak perempuan tidak terakomodir dalam kehidupan. Hukum dam pemerintahan tidak menjadikan perempuan setara. Terakhir dalam dual systems theory terdapat kolaborasi antara pandangan marxis dan radikal yang melihat bahwa opresi terhadap perempuan adalah akibat dari kapitalisme dan sistem patrarki.

Dalam pandangan feminisme, terdapat beberapa pertanyaan yang membingkai rangkaian teori gender yang menjadi wadah teori feminis. Pertama, dalam perbedaan gender, bagaimana pun posisi perempuan dan laki-laki selalu dibedakan sehingga 
perbedaan tersebut selalu ada. Kedua, mengenai ketidaksetaraan gender, hal tersebut terjadi karena relasi antara laki-laki dan perempuan, laki-laki mengobyekkan perempuan dan membuatnya sebagai “yang lain” (other) (Arivia, 2012). Oleh karenanya kebanyakan teori feminis memandang adanya keterlibatan kaum adam dalam dominasi di kehidupan kaum hawa. Ketiga, tentang penindasan gender, bagaimanapun banyaknya kasus tentang penganiayaan perempuan oleh laki-laki lebih banyak daripada sebaliknya. Keempat, pengalaman perempuan akan penindasan berbeda karena mereka berada susunan penindasan struktural masyarakat, seperti perbedaan pendidikan, status, kelas, dan lokasi global. Berdasarkan pandangan di atas maka para peneliti biasa mengambil posisi sebagai aktivis yang membantu kaum perempuan dari marginalisasi yang menghantui kehidupannya.

Pada awalnya teori komunikasi yang beraliran feminis lebih menekankan pada bagaimana hubungan antara gender, sex dan gaya berkomunikasi. Judith Butler salah seorang ilmuwan komunikasi yang memilih untuk menjadi lesbian, memandang bahwa ilmu komunikasi dalam perspektif gender adalah bagaimana seseorang menampilkan identitas pribadi dalam lingkup sosial yang dikenal sebagai Performance Theory. Teori ini menjadi payung dalam merujuk perilaku komunikasi seseorang. Butler memandang bahwa teori komunikasi bergerak di area bagaimana seorang individu menampilkan negosiasi, penolakan, dan perubahan identitasnya dalam masyarakat.

Perkembangan ini kemudian terus mengalir. Teori-teori feminis berupaya mendekonstruksi pengetahuan-pengetahuan yang mapan dengan menunjukkan bias maskulinitas dan politik gender yang membingkainya. Teori feminis merepresentasikan bahwa teori-teori yang dibangun adalah sebuah konstruksi pengetahuan yang bersandar pada susunan-susunan sosial, relasional,dan kekuasaan (Ritzer, 2012:777). Kajian kritis memang tidak terlepas dari adanya relasi sosial, politik, ekonomi. Menurut Gross dalam 
Arivia (2003, 83-84) perkembangan teori feminis, ada upaya-upaya untuk memasukkan agenda sebagai berikut:

1. Perempuan dan feminitas menjadi obyek teori dan penelitian yang luas.

2. Perempuan dan feminitas telah sekian lama diekslusi dan diabaikan dalam teori tradisional kini dikonsepsikan sebagai setara dengan penelitian-penelitian seperti kajian sosial-ekonomi.

3. Wacana partriakal sendiri mendapat kritik yang tajam dan ada upaya-upaya untuk membuat kerangka kerja teori wacana feminis secara ontologism, epistemologis, dan politis.

4. Teori feminism ingin melihat pendekatan wacana patriarchal melalui pengaitan dengan perempuan.

5. Wacana dikotomis "either/or" yang selama ini sering digunakan harus ditolak atau diadakan penyesuaian.

\section{Diskusi}

Pendekatan feminis bertujuan untuk meningkatkan hubungan yang kolaboratif dan non eksploitatif, sehingga peneliti ditempatkan sedemikian rupa untuk menghindari objektifikasi dan mengarahkan penelitian pada kajian yang transformatif. Fox-Keller (1985) menyatakan "Feminist researchers see gender as a basic organizing principle that shapes the conditions of their lives. It is a lens that brings into focus particular questions" (Creswell, 2013:29). Berdasarkan latar belakang di atas maka muncul beberapa teori Komunikasi yang melakukan pendekatannya berdasarkan kesadaran feminis seperti Genderlect Theory, Poscolonial Feminism Theory dan beberapa teori lain yang akan dibahas berikut:

\section{Genderlect Styles Theory}


Debora tannen melihat bahwa percakapan antara perempuan dan laki-laki adalah komunikasi lintas budaya. Gaya bercakap-cakap perempuan dan lakilaki adalah bentuk wacana yang menunjukkan perbedaan yang mencolok antara perempuan dan laki-laki. Teori muncul karena adanya kesadaran bahwa dalam melakukan percakapan, terdapat posisi yang berbeda antara laki-laki dan perempuan, di mana posisi laki-laki dianggap lebih dominan daripada perempuan. Agenda perempuan dianggap tidak sepenting agenda laki-laki. Walaupun perempuan dan laki-laki memiliki kata yang sama dalam percakapannya, namun pemahaman terhadap kata tersebut berbeda. Beberapa catatan yang menjadi asumsi Tannen (Griffin, 2006) dirangkum sebagai berikut:

a. Perbedaan dunia menyebabkan perbedaan persepsi dalam percakapan antara perempuan dan laki-laki.

b. Perermpuan mengharapkan adanya koneksivitas dalam percakapan sementara di sisi lain laki-laki berharap mendapatkan status dan kebebasannya.

c. Perempuan berbicara untuk mendapatkan kenyamanan sementara lakilaki berbincang untuk menunjukkan kekuasaan dan kehebatan dirinya.

\section{Poscolonial Feminism Theory}

Teori ini berawal dari tulisan Edward Said mengenai Orientalisme (1978) dan akhirnya menjadi katalisator dan titik referensi bagi paham postcolonial. Aschroft, Griffiths \& Tiffin, (1989) menyatakan "Postcolonial theory refers to the study of 'all the cultures' affected by the imperial process from the moment of colonialization to the present day". Gandhi (1998: 34) melihat poskolonialisme melahirkan pemahaman yang sangat spesifik atas dominasi 
Barat sebagai gejala aliansi yang tidak menyeluruh antara kuasa dan pengetahuan. Menurut Madison (2012: 55) "Postcolonialism refers to the multiple forms and locations of discourse, performance, politics, value, and the "everyday" - both past and present- that emanate from the history of colonialism". Oleh karenanya kajian pascakolonial mengabdikan pengetahuannya pada pengalaman imperialism, eurosentrisme dan proses kolonialisasi maupun dekolonialisasi. Kesemuanya itu mengerucut pada adanya dominasi ideologi.

Dalam jurnal McEwan (2001) yang berjudul "Post colonialism, Feminism, and Development” dibahas pendapat Gayatri Spivak (1990) yang mengecam posisi biner dalam penamaan negara. Dunia Barat membagi wilayah dengan menamai negara-negara bekas jajahan sebagai "The Third World". Teori Pascakolonial dalam jurnal ini menjelaskan bagaimana hegemoni berdasarkan sejarah dan kekuasaan (timeline \& knowledge) yang mengkonstruksi dunia ketiga. Menyitat pendapat Said (1993) bahwa pengetahuan adalah salah satu bentuk kekuasaan. Ide pembangunan adalah milik Barat, sehingga pascakolonial seakan-akan mengganggu kelanggengan kontrol Barat terhadap Timur. Perempuan di dunia ketiga melalui tulisan McEwan ini diajak untuk memahami lokasi, peran ekonomi, dimensi identitas sosialnya baik secara politik ekonomi dan secara global. Artinya perkembangan bangkitnya negara-negara dunia ketiga merupakan kesempatan bagi perempuan untuk berkembang dan mengembangkan pengetahuannya. Hal yang perlu dipahami dari kajian pascakolonialisme adalah: 
a. Pengalaman kolonial dipahami sebagai dominasi ideologi. Ideologi penjajah berada pada posisi lebih atas. Pengetahuan lokal dianggap liar, tidak beradab, dan tidak berbudaya.

b. Struktur sejarah diciptakan, dipertahankan dan dilanjutkan untuk mereproduksi pengalaman kolonial, terutama di daerah bekas jajahan. Rakyat negara jajahan pada akhirnya memiliki mind set inferior pada ras penjajahannya.

c. Adanya oposisi biner "First World" dan "Third World", yang diciptakan untuk membedakan kehidupan yang beradab dan tidak beradab. Negara yang maju dan negara berkembang. Oleh karena itu muncul perbedaan secara terus menerus. Perbedaan ini menciptakan hubungan yang tidak setara.

Ketika postkolonial ini masuk ke dalam ranah feminisme akan nampak bahwa perempuan dunia ketiga adalah korban dari opresi ganda. Opresi ideologi kolonial dan patriarki asing. Perempuan pribumi menderita akibat adanya orang Barat. Sebab di tanah koloni perempuan pribumi juga melayani kaum Barat dan patriarki-feodalisme.

\section{Black Femnism Theory}

Teori komunikasi juga membongkar cara-cara perempuan mengakses ranah publik dan kiprah perempuan dalam politik. Misalnya bagaimana perempuan keturunan Afro Amerika berkiprah di ranah publik begitu juga perempuan keturunan Amerika Latin. Kemunculan ini akibat adanya tekanan-tekanan yang kuat berasal dari pengistimewaan perempuan kulit putih yang dianggap lebih beradab, berpengetahuan dan istimewa dibanding perempuan kulit berwarna. Menariknya politik perbudakan di Afrika dan Amerika Latin 
menjadi salah satu dasar munculnya kajian Black Feminism atau feminisme kulit hitam. Para aktivis feminisme kulit hitam seperti Barbara Smith, Audre Lorde, Gloria I. Joseph berupaya menjembatani memobilisasi persoalanpersoalan yang mereka anggap mempunyai dampak langsung terhadap keseluruhan kualitas hidup kebutuhan perempuan kulit hitam.

Salah satu riset yang menjelaskan bagaimana perempuan kulit hitam menjadi objek sensualitas dalam dunia film dan musik di Amerika serikat menunjukkan bahwa posisi perempuan kulit berwarna di masyarakat modern belum setara. perempuan kulit hitam yang diwakili oleh sosok Rihanna seorang artis papan atas dunia masih mengalami beragam pelecehan. Baik secara langsung maupun tidak langsung. Fleetwood (2012) menyatakan:

"Three dominant frameworks have been employed to analyze Rihanna's onstage and offstage performances and personae since the assault: an universalizing narrative of domestic violence victimization; a familiar narrative of black female survival; and a coercive agenda that I call black recuperative heterosexuality".

\section{Mute Group Theory dari Cherish Kramarae}

Teori ini menjelaskan ketidaksesuaian antara perilaku perempuan yang diharapkan oleh laki-laki dan apa yangsebenarnya dilakukan oleh perempuan. Menurut Shirley dan Edwin Ardener (Sobur, 2014) setiap masyarakat mempunyai ideology dominan yang mendeskripsikan semua perilaku social. Ideology tersebut membentuk pemikiran mengenai norma-norma dan harapan social, memasok kosakata yang digunakan serta merelfeksikan citra realitas yang digenggam oleh kelompok dominan. Pada Intinya menurut West dan Turner (2007) teori ini menyatakan bahwa bahasa melayani penciptanya. Terkadang kelompok bungkam ini menciptakan bahasa mereka sendiri untuk menghadapi permasalahan mereka dengan bahasa kelompok dominan. 
Berdasarkan penelitiannya Kramarae (West dan Turner, 2007) berasumsi bahwa:

a. Perempuan mempersepsikan dunia secara berbeda dibandingkan laki-laki karena pengalaman pria dan wanita yang berbeda serta adanya kegiatankegiatan yang berakar pada pembagian pekerjaan.

b. Karena dominasi politik mereka, maka sistem persepsi pria dominan menghambat ekspresi bebas dari model alternative perempuan mengenal dunia.

c. Agar dapat berpartisipasi di masyarakat maka perempuan harus mentransformasi model mereka sendiri sesuai dengan system ekspresi pria yang diterima.

5. Stand point Feminism Theory dari Sandra Harding dan Julia Wood

Sandra Harding dan Julia T. Wood mengklaim bahwa dalam kita dibentuk melalui kuasa di mana pengalaman dan pengetahuan serta bagaimana kita berkomunikasi serta memahami diri kita, orang sekitar kita dan dunia di dalam sebuah kelompok sosial. Di sinilah kita berdiri dan merasa memiliki pengetahuan dan jati diri. Secara garis besar manusia mencari kebebasan/otonomi serta relasi/ keterhubungan dalam kehidupannya. Walaupun demikian Wood (Griffin, 2006:485) memposisikan bahwa "men tend to want more autonomy, women tend to want more connectedness". Walaupun demikian tidak semua perempuan memiliki titik pandang yang sama dalam hal keterhubungan tersebut. Asumsi dari teori ini berdasarkan kajian Littlejohn dan Foss, (2008) adalah sebagai berikut:

a. Lingkungan kehidupan mempengaruhi bagaimana seorang perempuan mengkonstruksi dunia sosialnya 
b. Seseorang (perempuan) memiliki multiple identity. Identitas ini sesuai dengan tingkat sosial dan hubungan sosial yang dijalankannya.

c. Mindfulness dimaknai sebagai sesuatu yang merupakan rutinitas seharihari dan dilakukan secara sadar.

Harding (Griffin, 2006: 483) juga menjelaskan bagaimana posisi perempuan dalam percakapan dengan laki-laki akan berbeda, "when people speak from the opposite sides of power relations, the perspective from the lives of less powerful can provide a more objective view than the perspective from the lives of the more powerful".

Fenomena yang menarik dalam perkembangan teori Komunikasi adalah keberadaan Teori Queer dalam agenda kaum feminis. Teori ini berasumsi bahwa dunia telah menganggap bahwa heteroseksual adalah konstruksi yang dianggap normal dalam masyarakat sehingga muncullah pandangan yang lebih cair terhadap keberadaan identitas seksual lain. Judith Butler adalah salah satu tokohnya dan berpijak pada pemikiran bahwa gender bukanlah sesuatu yang alamiah karena gender dikonstruksikan. Sebagai golongan yang dimarginalkan kaum lesbian, gay, biseksual, dan transgender (LGBT) berharap memiliki ruang di media dan dalam budaya kontemporer masa kini. Masalah seputar pandangan yang salah/stereotipe, mendiskreditkan juga masalah bahwa kaum LGBT bukan sebagian dari budaya mainstream. Secara metodologi Queer Theory memberikan alternatif dalam menghubungkan, mengumpulkan dan menampilkan informasi yang muncul dari fenomena hubungan sosial yang berbeda.

\section{Kesimpulan}

Secara epistemologis riset-riset dengan objek perempuan tidak berarti semuanya masuk ke dalam ranah kritis. Hal yang penting dilakukan bagi riset kritis adalah apakah riset tersebut mampu membongkar ketidakadilan bagi perempuan adalah titik pandang utama. 
Feminisme memang beraliran kritis, akan tetapi tidak menutup kemungkinan untuk melakukan riset dengan ranah konstruktivis karena masih banyak kajian tentang perempuan yang perlu dikonstruksikan. Pengalaman-pengalaman unik perempuan pun masih membutuhkan pendekatan fenomenologis untuk membuka jalan bagi terciptanya solusi. Tujuan utama dari sebuah riset adalah memberikan solusi oleh karena itu riset yang meneliti mengenai perempuan sebaiknya adalah yang mampu mengangkat perempuan dari keterpurukan dan memperbaiki taraf kehidupan perempuan. Dengan demikian apa yang menjadi impian kaum feminis dapat tercapai, yaitu memperbaiki posisi perempuan dalam kehidupan berbangsa dan bernegara.

\section{Daftar Pustaka}

Ashcroft, Bill. Garreth Griffiths \& Helen Tiffins. (2000). The Key Concepts in Post Colonial Studies. Routledge. London

Creswell, John. (2013). Qualitative Inquiry and Research Design: Choosing among five approaches $3^{\text {rd }}$ Edition. Sage Publication Inc. LA, London, New Delhi, Singapore

Fleetwood, Nicole R. "The Case Of Rihanna: Erotic Violence And Black Female Desire." African American Review 45.3 (2012): 419-435. Academic Search Premier. Web. 29 Oct. 2013

Gandhi, Leena. (2007). Teori Pascakolonial, Upaya meruntuhkan Hegemoni Barat. Qalam. Jakarta

Griffin. (2006). First Look at Communication Theory $6^{\text {th }}$ Edition. McGraw Hill. NY, USA

Hill Collins, P. (1999). Black Feminist Thought: Knowledge, Consciousness and the Politics of Empowerment, . New York: Routledge.

Ida, Rahma. (2014). Studi Media dan Kajian Budaya. Jakarta: Prenada Media Grup

Madison, Soyini. (2012). Critical Ethnography Method, Ethics, and Performance 2nd Edition. Sage Publication. USA

McEwan, Cheryl (2001). "Postcolonialism, feminism, and development: intersections and dilemmas". Progress in Development Studies 1 (2):93-

111.doi:10.1177/146499340100100201. 
Littlejohn, Stephen \& Karen Foss. (2009). Encyclopedia of Communication Theory. Sage Publisher. California

Putnam Tong, Rosemary. (1998). Feminist Thought: Pengantar Paling Komprehensif kepada Aliran Utama Pemikiran Feminis. Jalasutra Yogyakarta

Ramazanoglu, Caroline \& Janet Holland. (2002). Feminist Methodology Challenges \& Choices. Sage Publication Inc. LA, London, New Delhi, Singapore

Ritzer, George. (2012). Teori Sosiologi dari Sosiologi Klasik sampai Perkembangan Terakhir Postmodern Edisi kedelapan. Pustaka Pelajar. Yogyakarta.

Said, Edward. (1993). Culture and Imperialism. New York: Alfred A. Knopf Inc.

Sobur, Alex. (2014). Komunikasi Naratif Paradigma, Analisis dan Aplikasi. Remaja Rosdakarya. Bandung

Thornham, Sue. (2010). Teori Feminis dan Cultural Studies tentang Relasi yang belum Terselesaikan. Jalasutra. Yogyakarta

West, Richard \& Lynn Turner. (2007). Introducing Communication Theory Analysis \& Application $3^{\text {rd }}$ Edition. McGraw Hill. USA 